\title{
Education for the global village: distance learning and the Internet
}

\section{Nigel Mason}

Nigel J. Mason, "Education for the global village: distance learning and the Internet," Proc. SPIE 9663, Eighth International Topical Meeting on Education and Training in Optics and Photonics, 96630 (6 October 2003); doi: $10.1117 / 12.2208380$

SPIE Event: Eighth International Topical Meeting on Education and Training in Optics and Photonics, 2003, Tucson, Arizona, United States 


\title{
Education for the global village: distance learning and the Internet
}

\author{
Nigel J. Mason \\ Department of Physics and Astronomy, The Open University, Walton Hall, Milton Keynes, MK7 6AA, United Kingdom \\ telephone:44-0-1908-655132; fax: 44-0-1908-654192; e-mail: n.j.mason@open.ac.uk
}

\begin{abstract}
Advances in optics and photonics technology requires the development of 'life long learning' techniques to maintain well trained technical (and management) staff. Such training may not be provided by 'traditional' lecture programmes. Distance learning allows study from home or the work place providing flexibility to both employer and employee.

(C)2003 Optical Society of America

OCIS codes: (000.2060) Education
\end{abstract}

The Open University is the UK's largest distance learning provider with over 30 years experience in teaching science at distance. In this talk I will review the experience of the Open University in providing distance learning with particular emphasis on its long running and highly successful optics based courses (e.g. 'Images and information' and 'Imaging in medicine'). The revision of such courses in an age of rapid technological change will be discussed and how to make such courses applicable to specific industries reviewed. Issues arising when training people from a diverse range of academic backgrounds will be described. The need for, and provision of, practical schools will be discussed. The role of academic and industrial staff in designing and developing such courses will also be presented. Finally the future development of such courses through more extensive use of the internet (and egrid) will be presented and the challenges discussed. 